\title{
Presentación benigna de anomalia potencialmente maligna
}

\author{
Benign presentation of potentially malignant anomaly
}

Palabras Clave: Anomalía congénita coronaria, Angiografía por tomografía computarizada cardíaca, Muerte súbita de origen cardiaco.

Key words: Congenital coronary anomaly, Cardiac computed tomography angiography, Cardiac sudden death.

A 57-year-old female with no past medical history and no symptoms, who was referred to the Internal Medicine Consultation for the presence of albuminuria with a creatinine clearance of $87.3 \mathrm{~mL} / \mathrm{min}$. It was detected grade II arterial hypertension and started indapamide and perindopril. The complementary study carried out evidenced a horseshoe kidney on renal ultrasound and a double contour image in the aortic root (anterior Valsalva sinus) on transthoracic echocardiography (Fig. 1), besides left atrial enlargement. To clarify this lesion, a cardiac computed tomography angiography was done (Fig. 2). This showed a common origin of the coronary arteries in a single ostium in the right coronary sinus, in which the common trunk of the left coronary artery has a long trajectory between the right ventricular outflow tract and the aorta. There was no evidence of extrinsic static compression images and no evidence of atherosclerotic disease. She underwent a cardiac stress test that not showed signs of myocardial ischemia or dysrhythmias. A conservative approach was adopted with vigilance and control of arterial hypertension and cardiac frequency with perindopril, indapamide and bisoprolol. Current follow-up of 5 years without intercurrences.

Coronary anomalies are rare and mostly asymptomatic as they are often diagnosed incidentally. Its clinical significance depends on the origin, course and amount of perfused myocardium. The symptoms result from myocardial ischemia and manifest as angina, arrhythmias, syncope, infarction or sudden death ${ }^{1}$.

The single coronary artery is a very rare congenital anomaly with an incidence between $0.0024-0.044 \%{ }^{2}$. The obstruction of this single vessel is devastating due to the absence of collaterals. In addition, the inter-arterial pathway may, in the presence of a hypertensive peak, compromise myocardial perfusion and thus culminate in sudden death ${ }^{1}$. The surgical revascularization can be considered in these cases mainly if there is evidence of ischemia ${ }^{3}$.

The interesting point of our patient is that she has two potentially malignant anomalies (single coronary artery and inter-arterial course of the left coronary artery) and have none cardiovascular event so far.

\section{Marques de Sousa S, Marques C.}

Serviço de Medicina Interna do Centro Hospitalar Póvoa de Varzim I Vila do Conde, Portugal
Figure 1. Transthoracic Echocardiography: a double contour image at the aortic root - anterior Valsalva sinus (orange circle)

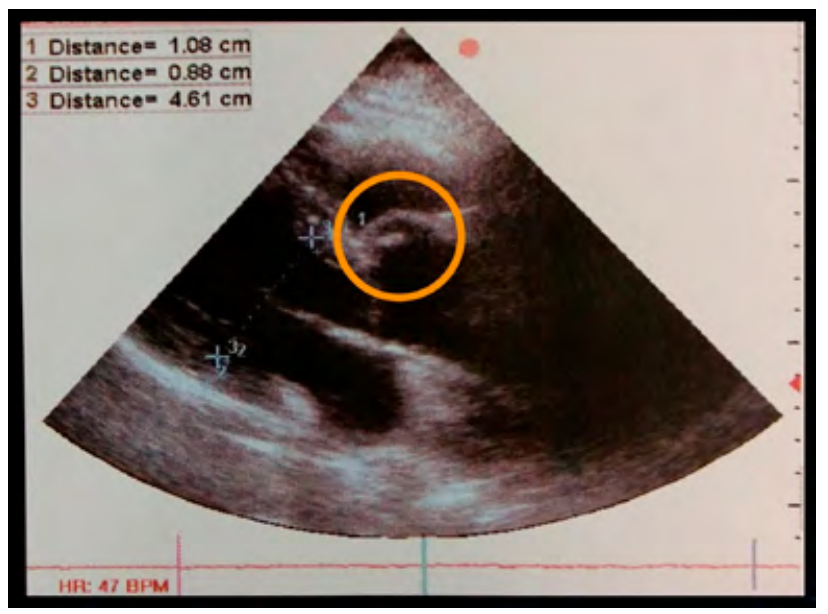

Figure 2. Computed tomography angiography: common origin of the coronary arteries in the single ostium in the right coronary sinus.

Common trunk of the left coronary artery with a long pathway between the right ventricular outflow tract and the Aorta. Ao - Aorta. CD -

Right Coronary Artery. Cx - Left Circumflex Artery. DA - Left Anterior Descending Artery. TCce - Common trunk of the Left Coronary Artery.

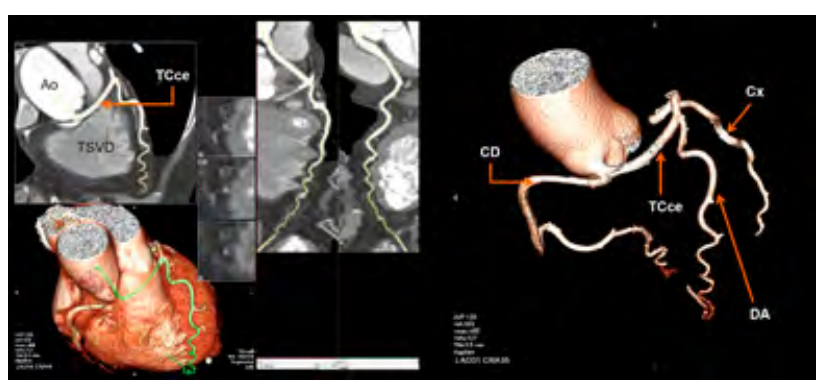

\section{REFERENCES}

1. Vieira C, Nabais S, Salgado A, Salomé N, Sousa P, Madureira AJ, et al. Origem coronária anómala: da suspeita à revascularização cirúrgica. Rev Port Cardiol. 2014 Jan 14;33(1):53.e1-5. Portuguese.

2. Desmet W, Vanhaecke J, Vrolix M, Van de Werf F, Piessens J, Willems J, et al. Isolated single coronary artery: a review of 50000 consecutive coronary angiographies. Eur heart J. 1992 Dec 1;13:1637-40.

3. Warnes CA, Williams RG, Bashore TM, Child JS, Connolly HM, Dearani JA, et al. ACC/AHA 2008 guidelines for the management of adults with congenital heart disease: a report of the American College of Cardiology/American Heart Association Task Force on Practice Guidelines (Writing Committee to Develop Guidelines on the Management of Adults With Congenital Heart Disease) Developed in Collaboration With the American Society of Echocardiography, Heart Rhythm Society, International Society for Adult Congenital Heart Disease, Society for Cardiovascular Angiography and Interventions, and Society of Thoracic Surgeons. J Am Coll Cardiol. 2008 Dec 2;52(23):e143-e263. 